\title{
Type I gamma phosphatidylinositol phosphate kinase modulates invasion and proliferation and its expression correlates with poor prognosis in breast cancer
}

Yue Sun ${ }^{1 \dagger}$, Dmitry A Turbin ${ }^{2 \dagger}$, Kun Ling ${ }^{1}$, Narendra Thapa ${ }^{1}$, Samuel Leung ${ }^{2}$, David G Huntsman², Richard A Anderson ${ }^{1 *}$

\begin{abstract}
Introduction: The loss of E-cadherin based cell-cell contacts and tumor cell migration to the vasculature and lymphatic system are hallmarks of metastasis of epithelial cancers. Type I gamma phosphatidylinositol phosphate kinase (PIPKly), an enzyme that generates phosphatidylinositol 4,5-bisphosphate $\left(\mathrm{PI}_{4}, 5 \mathrm{P}_{2}\right)$ a lipid messenger and precursor to many additional second messengers, was found to regulate E-cadherin cell-cell contacts and growth factor-stimulated directional cell migration, indicating that PIPKl $\gamma$ regulates key steps in metastasis. Here, we assess the expression of PIPKly in breast cancers and have shown that expression correlated with disease progression and outcome.
\end{abstract}

Methods: Using a tissue microarray, we analyzed 438 breast carcinomas for the levels of PIPKly and investigated the correlation of PIPKly expression with patient survival via Kaplan-Meier survival analysis. Moreover, via knockdown of the expression of PIPKly in cultured breast cancer cells with siRNA, the roles of PIPKly in breast cancer migration, invasion, and proliferation were examined.

Results: Tissue microarray data shows that $\sim 18 \%$ of the cohort immunostained showed high expression of PIPKl $\gamma$. The Kaplan-Meier survival analysis revealed a significant inverse correlation between strong PIPKly expression and overall patient survival. Expression of PIPKly correlated positively with epidermal growth factor receptor (EGFR) expression, which regulates breast cancer progression and metastasis. In cultured breast cancer cells, PIPKly is required for growth factor stimulated migration, invasion, and proliferation of cells.

Conclusions: The results reveal a significant correlation between PIPKly expression and the progression of breast cancer. This is consistent with PIPKIy 's role in breast cancer cell migration, invasion, and proliferation.

\section{Introduction}

Breast cancer is one of the most significant malignancies of women $[1,2]$. Despite successful treatment of the primary malignancy, tumors relapse and subsequent metastasis often occur at distant sites, including bone, lung, liver, and brain [3-5]. The presence of breast cancer metastasis significantly influences patients' prognosis. The five-year survival rate from breast cancer drops

\footnotetext{
* Correspondence: raanders@wisc.edu

+ Contributed equally

'Department of Pharmacology, University of Wisconsin Medical School, 1300 University Avenue, Madison, Wisconsin, 53706, USA
}

from $96 \%$ to $75 \%$ with regional spread, and drops to $20 \%$ with distant spread $[6,7]$. Understanding the molecular mechanism that regulates breast cancer metastasis is critical to developing therapies to treat breast cancer and increase the survival rate; and defining markers that predict metastatic potential will be a key for defining therapeutic approaches.

Phosphatidylinositol 4,5-bisphosphate ( $\left.\mathrm{PI} 4,5 \mathrm{P}_{2}\right)$ plays central roles in regulating cell migration, a key step of cancer metastasis, by modulating adhesion turnover and dynamic cytoskeleton rearrangements [8]. By interacting with cofilin, $\mathrm{PI} 4,5 \mathrm{P}_{2}$ regulates the elongation of newly 
polymerized actin filaments via controlling cofilin cellular distribution and activation $[9,10]$. Including cofilin, $\mathrm{PI}, 5 \mathrm{P}_{2}$ also regulates the reorganization of actin cytoskeleton by associating with other proteins such as $\alpha$ actinin, WASP/N-WASP, gelsolin, profilin, and villin $[8,11]$. Furthermore, $\mathrm{PI} 4,5 \mathrm{P}_{2}$ regulates adhesion turnover by binding to and modulating talin, vinculin, ezrin/ radixin/moesin, calpain, and other proteins involved in adhesion dynamics $[8,11]$.

Type I gamma phosphatidylinositol phosphate kinase (PIPKI $\gamma$ ) is one of the major enzymes in cells that generate $\mathrm{PI}, 5 \mathrm{P}_{2}$ by phosphorylation of phosphatidylinositol (4)phosphate [12]. Via the spatial and temporal control of PI4,5P 2 synthesis, PIPKI $\gamma$ plays a key role in multiple biological processes $[8,13-18]$. Loss of PIPKI $\gamma$ leads to defects of cardiovascular and neuronal development, which is consistent with changes in cadherin function and cell migration [19]. PIPKI $\gamma$ is also required for the integrity of the membrane cytoskeleton [20]. The PIPKI $\gamma$ is alternatively spliced in cells, resulting in at least two major variants, PIPKI $\gamma 635$ and PIPKI $\gamma 661$ (now named PIPKI $\gamma$ i1 and PIPKI $\gamma$ i2), which differ by a 26 amino acid C-terminal extension $[21,22]$. The short splicing variant PIPKI $\gamma \mathrm{i} 1$ is reported to be a major contributor of the $\mathrm{PI}, 5 \mathrm{P}_{2}$ pool that supports $\mathrm{G}$ protein-coupled receptormediated inositol 1,4,5-trisphosphate generation and plays a critical role in $\mathrm{Ca}^{2+}$ flux [23]. Unlike PIPKI $\gamma \mathrm{i} 1$, PIPKI $\gamma$ i2 binds to talin via the 26 amino acid C-terminal extension in a process regulated by tyrosine phosphorylation, targeting PIPKI $\gamma$ i2 to adhesions $[17,24]$. The phosphorylation is mediated by both growth factor receptors and by the non-receptor tyrosine kinase, Src $[8,17,18]$. By generating $\mathrm{PI}_{4}, 5 \mathrm{P}_{2}$ and regulating talin assembly, PIPKI $\gamma$ i2 modulates nascent adhesion formation at the leading edge to facilitate cell migration. Specifically, the PIPKI $\gamma \mathrm{i} 2$ regulates epidermal and other growth factor stimulated chemotaxis [25], a process key to intravasation of cancer cells where cells migrate into the vasculature and lymphatic system, a first step in the metastasis of breast cancers [9].

The loss of E-cadherin cell-cell contacts is a hallmark for the progression of cancers of epithelial origin [26]. Remarkably, the PIPKI $\gamma$ also regulates the ability of epithelial cells to assemble E-cadherin-based cell-cell contacts [16]. This occurs by an association of PIPKI $\gamma$ i2 with E-cadherin and the recruitment of specific clathrin adaptors required for basolateral and endocytic trafficking by an association with the PIPKI $\gamma$ i2 C-terminus. A loss of PIPKI $\gamma$ expression leads to a loss of E-cadherin targeting to the plasma membrane and a loss of E-cadherin-based cell-cell contacts [16]. Thus, PIPKI $\gamma$ regulates the plasma membrane targeting of E-cadherin-based cell-cell contacts and the polarization of epithelial cells. The positioning of the PIPKI $\gamma$ as a regulator of both E-cadherin cell-cell contact assembly and growth factor stimulated cell migration positions the PIPKI $\gamma$ as a key-signaling molecule in physiological functions that are fundamental to the metastasis of cancers of epithelial origin.

In spite of the increasing evidence indicating that PIPKI $\gamma$ plays a crucial role in cell migration so that it is likely implicated in cancer metastasis, the pathological correlation between the lipid kinase and cancer progression remains uninvestigated. Here, we analyzed breast carcinomas via tissue microarray analyses for the levels of PIPKI $\gamma$ and demonstrated a significant inverse correlation between strong positive PIPKI $\gamma$ expression and overall survival. In addition, the requirement of PIPKI $\gamma$ for the migration, invasion, and growth of breast cancer cells has been confirmed using in vitro models.

\section{Materials and methods Antibody}

Polyclonal PIPKI $\gamma$ anti-serum was generated from rabbit (Covance, Princeton, NJ, USA) using purified His-tagged PIPKI $\gamma$. Anti-serum was purified on an affinity column generated by coupling recombinant $\mathrm{C}$-terminus of PIP$\mathrm{KI} \gamma$ to cyanogen bromide-activated Sepharose $4 \mathrm{~B}$ (Sigma-Aldrich, Saint Louis, MO, USA) as described $[17,25,27]$. The affinity-purified antibody recognizes both PIPKI $\gamma \mathrm{i} 1$ and PIPKI $\gamma \mathrm{i} 2$.

\section{Constructs}

The siRNA sequence targeting PIPKI $\gamma$ is 5'-GGACCUGGACUUCAUGCAG-3'. The sequence of control scrambled siRNA is 5'-GUACCUGUACUUCAUGCAG3'. Oligonucleotide sequences used for generation of short hairpin RNA (shRNA) specific for PIPKI $\gamma$ were: GCCACCTTCTTTCGAAGAA (PIPKI $\gamma$ shRNA) and GCCTTCTTCGCTAAACGAA (Control shRNA). Generation of replication-defective infectious viral particles and the transduction of the cells were carried out following the protocol provided by Addgene (Addgene Inc., Cambridge, MA, USA). In brief, synthesized oligonucleotides were annealed and cloned into $\mathrm{HpaI}$ and XhoI sites of pLL3.7 vector (Addgene Inc., Cambridge, MA, USA). Stabl3 competent cells (Invitrogen, Carlsbad, CA, USA) were used for transformation and DNA purification to minimize the mutagenesis. The integrity of lentiviral vector-containing cloned shRNA sequences were validated by DNA sequencing.

\section{Cell cultures and transfection}

MDA-MB-231 and MDA-MB-435S cells were cultured using DMEM supplemented with 10\% FBS. SKBR3 cells were cultured in DMEM/F12 with 10\% FBS. For siRNA transfection, cells were transfected with Oligofectamine (Invitrogen, Carlsbad, CA, USA) following the manufacturer's instructions. 


\section{Patient information and tissue microarrays}

A tissue microarray was constructed out of 438 archival invasive breast carcinoma samples at Vancouver General Hospital. These cases were collected between 1974 and 1995. Ethics board approval was obtained for all cases. Patients' demographics, pathological features of the tumors and expression of various biomarkers have been reported previously [28]. In brief, median age of the patients at the moment of diagnosis was 61.5 years; median survival time was 11.9 years. Histological distribution included 379 infiltrating ductal carcinoma, 41 infiltrating lobular carcinoma and 8 special types.

Three tissue microarray blocks were assembled using a manual tissue microarrayer (Beecher Instruments, Inc., Silver Springs, MD, USA) from formalin fixed paraffinembedded tissue as described previously [29]. Tissue sections $(4 \mu \mathrm{m}$ thick) were cut from the donor blocks and stained with hematoxylin and eosin for tissue review. Representative areas of tumor were circled on the slides and corresponding donor blocks; duplicate $0.6 \mathrm{~mm}$ cores were taken from these blocks and inserted into three recipient blocks. Sections ( $4 \mu \mathrm{m}$ thick) were cut from the recipient blocks and deparaffinized with CitriSolve and dehydrated through three alcohol changes. Antigen retrieval was performed using a steamer for 30 minutes in $0.1 \mathrm{M}$ citrate buffer ( $\mathrm{pH}$ 6.0). After that, sections were rinsed with PBS three times for five minutes each time. Hydrogen peroxide and serum free protein block (Dako, Carpenteria, CA, USA) were used to block endogenous peroxidases and prevent non-specific protein binding. Sections were then incubated with anti-PIPKI $\gamma$ antibody $(0.5 \mu \mathrm{g} / \mathrm{ml})$ in a sealed immunochamber overnight at $4^{\circ} \mathrm{C}$ and Dako Envision anti-rabbit secondary antibody was applied at room temperature for 30 minutes. The NovaRed Substrate Kit (Vector Labs, Burlingame, CA, USA) was used to visualize the protein. Slides were then counterstained with hematoxylin and mounted.

\section{Digital image database}

The hematoxylin and eosin and immunohistochemistry images of all cores used in this study are publicly available at the companion site [30]. The site was constructed using a GPEC database and a Java applet provided by Bacus Laboratories, Inc (Bacus Laboratories, Inc., Lombard, IL, USA). All the slides were scanned with a BLISS scanner (Bacus Laboratories, Inc., Lombard, IL, USA), and posted on the site. WebSlide Browser for Windows (Bacus Laboratories, Inc., Lombard, IL, USA) can be used for viewing preview images of the arrays and images of individual cores.

\section{Cell migration assay}

The assays were performed in modified Boyden chamber transwell (Neuroprobe, Gaithersburg, MD, USA) as described [31,32]. The membrane was pre-coated with type I collagen $(10 \mu \mathrm{g} / \mathrm{ml})$. Per well, 50,000 cells were applied. Chemotaxis assays were performed at $37^{\circ} \mathrm{C}$ in humidified air with $5 \% \mathrm{CO}_{2}$ for four hours. Cells migrated through to the underside of the membrane were counted in five high power fields, in a blinded fashion. The migration index for each experiment was calculated as the mean number of cells that migrated toward medium-containing $1 \%$ FBS divided by the mean number of cells that migrated toward medium-containing BSA only.

\section{Invasion assay}

Matrigel-coated Transwells (BD Bioscience, San Jose, CA, USA) were incubated with DMEM for four hours and $5 \times 10^{4}$ cells were plated in the upper chambers. The lower chambers contained 1\% FBS conditioned DMEM. The inserts were incubated at $37^{\circ} \mathrm{C}$ in humidified air with $5 \% \mathrm{CO}_{2}$ for 24 hours. The cells that had invaded the lower surface of the membrane were fixed with $4 \%$ polyformaldehyde and stained with $0.2 \%$ crystal violet. The number of cells that had invaded was quantified by counting random fields using a light microscope.

\section{Cell proliferation assay}

MDA-MB-231, MDA-MB-435S, or SKBR3 cells infected with lentivirus containing either control shRNA or PIPKI $\gamma$ shRNA were seeded into 12-well culture plates at a density of 1000 cells/well. Then, manual cell counting was performed every two days for eight days.

\section{Statistical analysis}

We performed Kaplan-Meier survival analysis using logrank test to determine differences in survival of the patients with different levels of PIPKI $\gamma$ protein expression. Breslow test was also used to emphasize survival differences in the first 5 to 10 years of the follow up. The alpha level was determined as $5 \%$. All the tests were two-sided. Spearman's correlation was utilized to estimate correlations between PIPKI $\gamma$ protein content with that of other biomarkers and clinical prognostic factors.

\section{Results}

\section{Expression of PIPKly in breast carcinomas}

The cellular functions of PIPKI $\gamma$ suggest the potential for roles in epithelial cancer progression. To explore the potential that PIPKI $\gamma$ may correlate with disease progression and outcome we began to assess the content of PIPKI $\gamma$ in a well-characterized tissue microarray of breast cancer patients. For this approach we used wellcharacterized antibody that specifically detect all splice variants of the PIPKI $\gamma$ as described in Materials and Methods. As a control, PIPKI $\gamma$ expression was knocked 
down with siRNA (Small interfering RNA) in breast epithelial (MCF10a) or carcinomas cell lines and this resulted in a loss of protein by western blotting and a loss of the immunostaining in these cells $[16,25]$.

Normal breast tissues show strong staining for E-cadherin epithelia cells lining the ducts and PIPKI $\gamma$ also shows strong staining of these cells (Figure 1a). To assess how the PIPKI $\gamma$ expression changes within breast cancers we have screened a breast cancer tissue microarray. The expression of PIPKI $\gamma$ in breast carcinomas was demonstrated via tissue microarray that was constructed out of 438 archival invasive breast carcinoma samples at the Vancouver General Hospital [33]. Of the 438 breast carcinoma represented on the tissue microarray, 330 specimens $(75.3 \%)$ were considered interpretable. As shown in the lower panels of Figure 1a, in

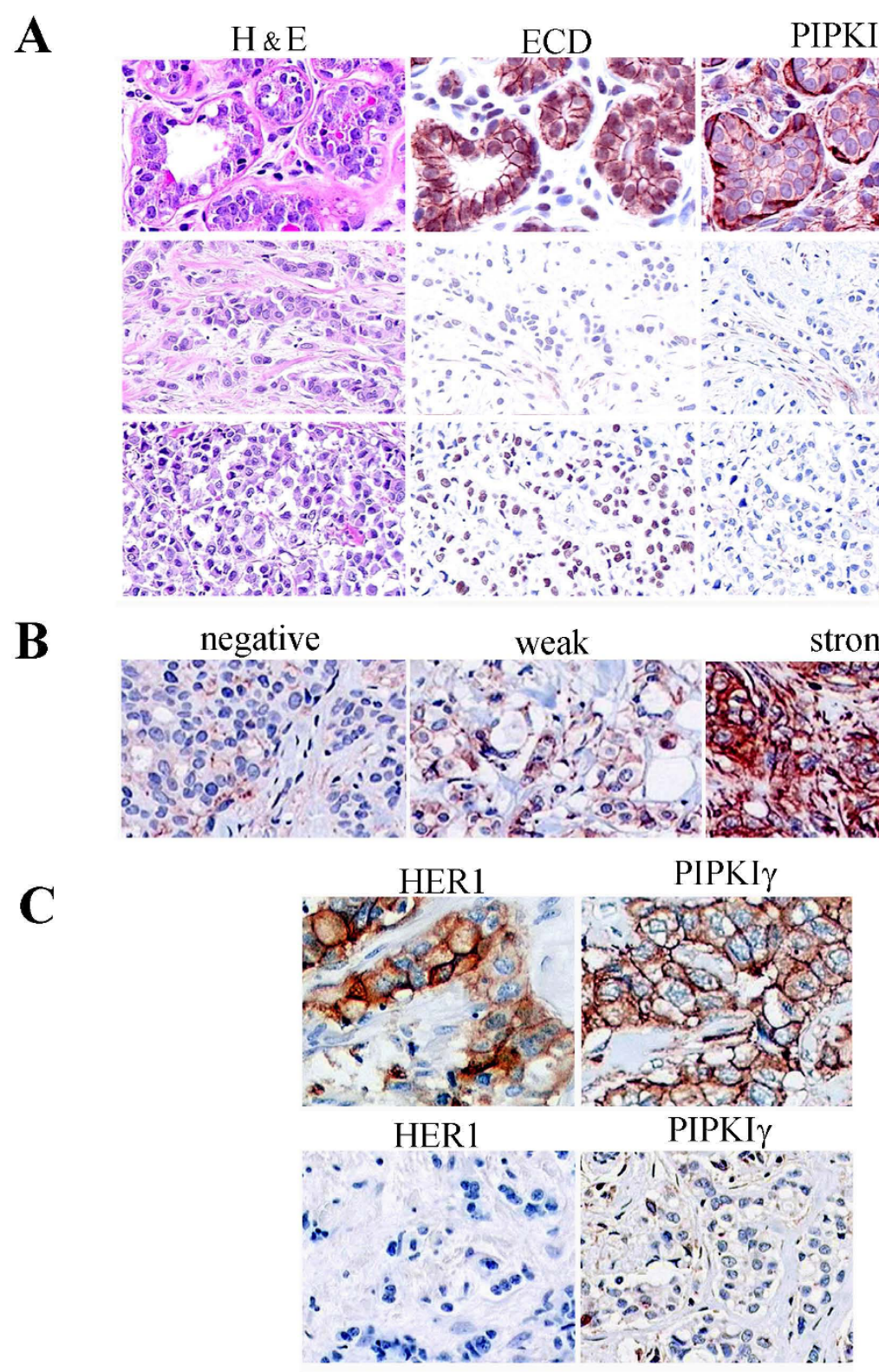

Figure 1 Expression of PIPKI $\gamma$ in breast carcinomas. (a) Shown is H\&E, E-cadherin and type I gamma phosphatidylinositol phosphate kinase (PIPKly) staining of normal breast tissue (top). Breast carcinomas that show a loss of both E-cadherin and membrane PIPKly (middle). A fraction of carcinomas that show both a mistargeting of E-cadherin and a loss of PIPKly (bottom). (b) Expression of PIPKly in breast carcinomas. (Left panel) Representative breast carcinomas stained negative for PIPKly. (Middle panel) Representative breast carcinomas stained weakly positive for PIPKl $\gamma$. (Right panel) Representative breast carcinomas stained strong positive for PIPKly. (c) Immunohistochemical staining of breast tumor tissue for human epidermal growth factor receptor (HER-1) and PIPKly. The panels on the top or on the bottom are from the same tumors. The top panels show strong expression of HER-1 and PIPKly, whereas the bottom shows weak staining for both antigens. 
Table 1 Correlation of expression of PIPKI $\gamma$ protein with different biomarkers

\begin{tabular}{lccc}
\hline \multicolumn{1}{c}{ Biomarker } & \multicolumn{2}{c}{ PIPKl $\boldsymbol{y}$ negative and weak vs. strong staining } \\
\cline { 2 - 5 } & Spearman's correlation coefficient & $\boldsymbol{P}$ value & Number of cases \\
\hline E-cadherin negative vs. weak and strong staining & 0.106 & 0.046 & 351 \\
\hline ER at 1\% cut-off point & -0.256 & 0.000003 & 327 \\
\hline PR at 1\% cut-off point & -0.298 & 0.000001 & 256 \\
\hline EGFR (HER1) negative vs. weak and strong staining & 0.262 & 0.000003 & 306 \\
\hline HER2/neu & 0.171 & 0.003 & 309 \\
\hline Nottingham Grade & 0.185 & 0.001 & 346 \\
\hline Tumour size & 0.025 & 0.648 & 349 \\
\hline Nodal status & 0.012 & 0.828 & 314 \\
\hline
\end{tabular}

EGFR = epidermal growth factor receptor; ER = estrogen receptor; HER2 = human epidermal growth factor receptor 2; PIPKI $\gamma=$ type I gamma phosphatidylinositol phosphate kinase; $\mathrm{PR}=$ progesterone receptor.

tumors with a loss of E-cadherin there is also a loss of PIPKI $\gamma$ staining. The bottom panel of Figure 1a shows that in a fraction of tumors E-cadherin was expressed but not targeted to the plasma membrane and these tumors also lost PIPKI $\gamma$. These combined data are shown statistically in Table 1 .

In Figure 1b, examples of the different PIPKI $\gamma$ staining of breast tumors are shown. The slides were scored as 'negative' if no PIPKI $\gamma$ staining was detected, 'weak staining' if there was any amount of weak membranous staining and/or strong membranous staining in less than $50 \%$ of tumor cells, and 'strong staining' if there was strong membranous staining in $50 \%$ or more carcinoma cells. Among the 358 specimens analyzed, 149 specimens were PIPKI $\gamma$ staining negative (41.6\%), 144 specimens were PIPKI $\gamma$ staining weakly positive (40.2\%), and 65 specimens were PIPKI $\gamma$ staining strongly positive (18.2\%) (Table 2).

\section{Survival analysis}

To investigate if PIPKI $\gamma$ tissue content correlates to breast cancer prognosis, Kaplan-Meier survival curves were generated using PIPKI $\gamma$ antibody staining. As shown in Figure 2a, these curves show that strong positive PIPKI $\gamma$ expression was correlated to poor outcome (Log Rank chi-squared $=6.078, P=0.014$; Breslow chisquared $=7.454, P=0.006)$. It indicates that PIPKI $\gamma$ expression is inversely correlated to the survival of breast cancer patients. To further define the correlation of PIPKI $\gamma$ expression with breast cancer prognosis,

Table 2 Number of breast carcinomas cases stained with negative, weakly positive and strong positive PIPKI $\gamma$

\begin{tabular}{lcc}
\hline PIPKI $\boldsymbol{\gamma}$ staining & Cases & \% of total cases \\
\hline negative & 149 & 41.6 \\
weakly positive & 144 & 40.2 \\
strong positive & 65 & 18.2 \\
\hline
\end{tabular}

PIPKI $\gamma$ = type I gamma phosphatidylinositol phosphate kinase. patients were stratified based on the lymph node status. Kaplan-Meier survival curves were generated for lymph node negative and lymph node positive. As shown in Figure $2 b$, there was no significant difference in survival of the patients with PIPKI $\gamma$ strong positive and weak positive or negative tumor in lymph node negative subset $($ Log Rank chi-squared $=1.01, P=0.315$; Breslow chi-squared $=0.945, P=0.331$ ). In the lymph node positive subset, the longer term survival difference was not significant in the log-rank test (Log Rank chisquared $=2.154, P=0.142$, Figure $2 \mathrm{c}$ ); however, the 5and 10-year survival rate of PIPKI $\gamma$ strong positive patients is significantly lower than PIPKI $\gamma$ negative or weakly positive patients and had trend towards significance in Breslow test (Breslow chi-squared $=3.267, P=$ 0.071 , Figure 2c). Considering that the median age of the patients at the moment of diagnosis is 61.5 years, the longer-term survival as 20 or 25 years may not clearly reflect the survival of breast cancer because it is very close to the normal average human life limit. The 5- and 10-year survival rate difference supports that PIPKI $\gamma$ expression is inversely correlated to the survival of breast cancer patients.

\section{Correlation of PIPKI $\gamma$ expression with breast cancer biomarkers}

To further characterize PIPKI $\gamma$ expression in breast cancer, Spearman's correlation was used to demonstrate the correlation of PIPKI $\gamma$ expression with clinical characteristics such as lymph nodal status, tumor size and Nottingham tumor grade. As shown in Table 1, PIPKI $\gamma$ expression does not correlate significantly with lymph nodal status and tumor size. There is a weak significant correlation with the Nottingham grade.

PIPKI $\gamma$ expression was correlated with the expression of some established breast cancer biomarkers on a tissue microarray. From this analysis there was a correlation between the loss of PIPKI $\gamma$ with loss of E-cadherin expression and plasma membrane targeting. It is 

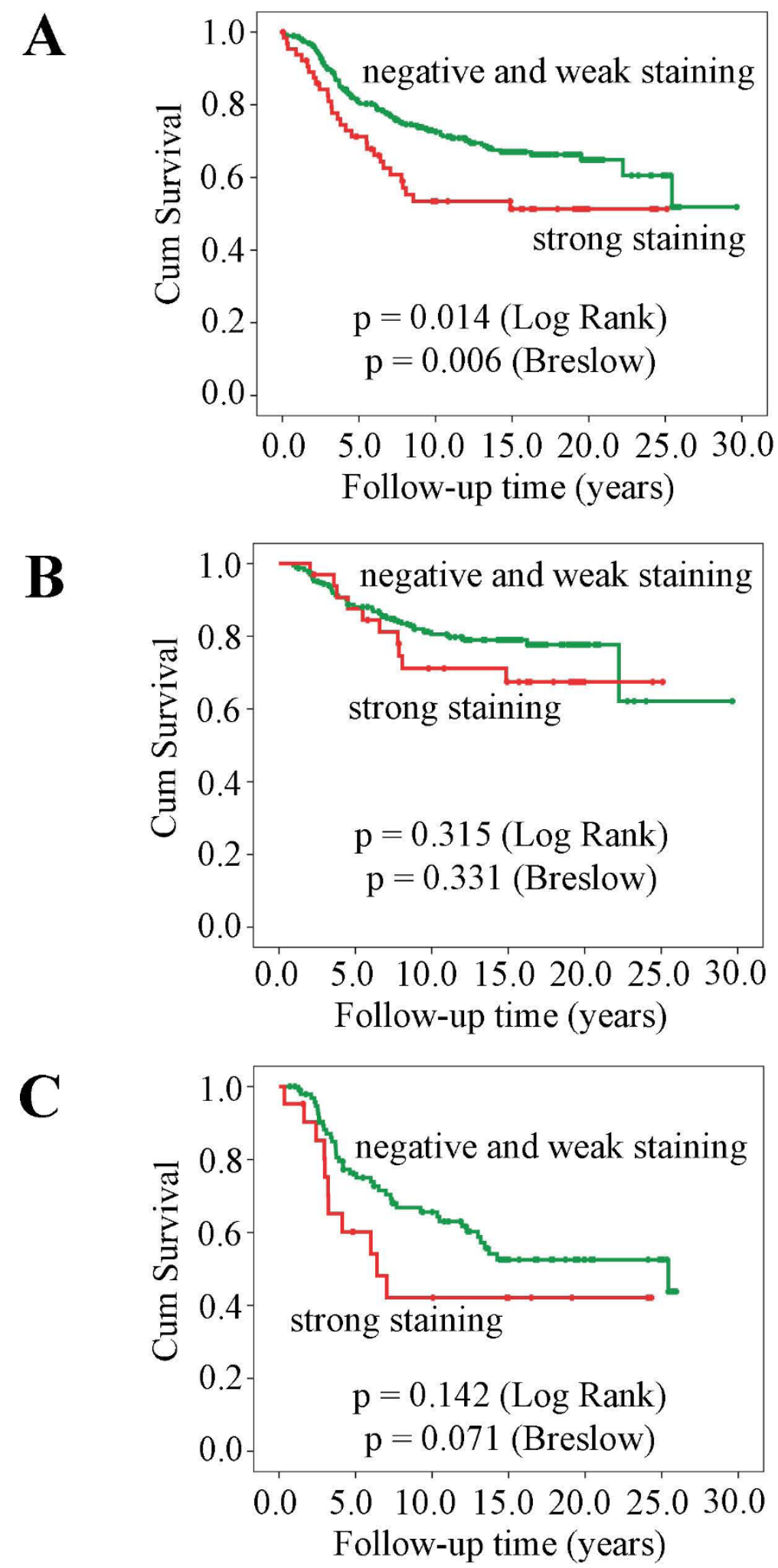

Figure 2 Kaplan-Meier survival curves for PIPKI $\gamma$ staining, with time given in years. (a) The entire cohort of patients. (b) Lymph node negative patients. (c) Lymph node positive patients. PIPKly = type I gamma phosphatidylinositol phosphate kinase. 
consistent with the finding that PIPKI $\gamma$ directly binds to E-cadherin and modulates E-cadherin trafficking [16]. Epidermal growth factor receptor (EGFR)/human epidermal growth factor receptor (HER) family receptors are often overexpressed in breast cancers and are used as breast cancer biomarkers [34]. Interestingly, our results show that both HER1 (EGFR) and HER2/neu expression are correlated with PIPKI $\gamma$ expression (Table 1). EGFR/HER family receptors play key roles in breast cancer metastasis and their expression are correlated with worse prognostic patient survival rates $[35,36]$. The correlation of PIPKI $\gamma$ with EGFR/HER family receptors is consistent with the finding that PIPKI $\gamma$ expression is inversely correlated to the survival of breast cancer patients. In addition, the results of tissue microarrays show that the expression of PIPKI $\gamma$ is inversely correlated to estrogen receptor (ER) and progestin receptor (PR). ER and PR status are important for distinguishing different breast cancer subtypes and they are critical for $\mathrm{ER}^{+}$or $\mathrm{PR}^{+}$breast cancer cell growth $[37,38]$. Our finding is the first time to discover a correlation between PIPKI $\gamma$ with ovarian hormone receptors ER and PR.

\section{PIPKI $\gamma$ regulates growth factor stimulated breast cancer migration and invasion}

Previously, it has been shown that PIPKI $\gamma$ is required for growth factor-induced HeLa (Helen Lane) cell migration [25]. As PIPKI $\gamma$ expression is inversely correlated to the survival of breast cancer patients, to regulate cancer cell metastasis might be one of the mechanisms for PIPKI $\gamma$ function in breast cancer. In order to verify this possibility, the effect of PIPKI $\gamma$ knockdown on two breast cancer cell lines, MDA-MB-231 and MDA-MB-435S, migration and invasion was demonstrated. As shown in Figure 3a, PIPKI $\gamma$-specific siRNA could specifically knockdown expression of PIPKI $\gamma$ in MDA-MB-231 or MDA-MB-435S cells, compared with the actin control. The effect of PIPKI $\gamma$-knockdown on breast cancer cell migration was quantified using a modified Boyden chamber transwell assay. As shown in Figure 3b, the knockdown of PIPKI $\gamma$ blocked migration of both MDAMB-231 and MDA-MB-435S. To investigate the effect of PIPKI $\gamma$-knockdown on breast cancer cell invasion, a Matrigel invasion assay was used. As shown in Figure 3c, the knockdown of PIPKI $\gamma$ also blocked invasion of both MDA-MB-231 and MDA-MB-435S.

\section{PIPKI $\gamma$ regulates breast cancer cell growth}

To further investigate the role of PIPKI $\gamma$ in the pathogenesis of breast cancer progression, lenti-virus-vectorbased PIPKI $\gamma$ shRNA was used to establish PIPKI $\gamma$ knockdown stable cell lines in MDA-MB-231, MDAMB-435S, and SKBR3 cells. The knockdown of PIPKI $\gamma$ expression in these stable cell lines was confirmed by western blot as shown in Figure 4. The effect of PIPKI $\gamma$ knockdown on breast cancer cell growth was then determined. As shown in Figure 4, PIPKI $\gamma$-knockdown decreased cell growth of MDA-MB-231, MDA-MB435S, and SKBR3 cells (Figures 4a to c). This result indicates an important role of PIPKI $\gamma$ in breast cancer cell proliferation and is consistent with the finding that PIP$\mathrm{KI} \gamma$ expression is inversely correlated to the survival of breast cancer patients.

\section{Discussion}

Here, we have shown that the expression of PIPKI $\gamma$ is inversely correlated to the survival of breast cancer patients, indicating a potential prognostic value of PIP$\mathrm{KI} \gamma$. Consistently, PIPKI $\gamma$ is required for breast cancer cell migration, invasion, and proliferation. All these results support the fact that PIPKI $\gamma$ plays an important role in breast cancer progression.

Overexpression of the EGFR has been shown to correlate with metastasis and poor prognosis of breast cancer [39]. Our results show that EGFR expression is correlated to PIPKI $\gamma$ expression in breast cancer cells, which hints that EGFR and PIPKI $\gamma$ may cooperate to facilitate breast cancer metastasis. Upon EGF stimulation, EGFinduced phosphorylation of PIPKI $\gamma$ causes a disassembly of the phospholipase C- $\gamma 1$-PIPKI $\gamma$ complex and this could enhance PI4,5 $\mathrm{P}_{2}$ accumulation and thus enhances talin assembly into adhesions and this in turn would facilitate the protrusion formation and stabilization of adhesions, which is required for cell migration [25].

Our results demonstrate that PIPKI $\gamma$ is not only required for breast cancer cell migration but also for breast cancer cell invasion. During invasion, cancer cells form actin-containing protrusions, called invadopodia, that extend into the extracellular matrix and participate in extracellular matrix degradation [40]. ADP-ribosylation factor 6 (ARF6) is a regulator of invadopodia formation and cell invasion [41] and ARF6 directly activates PIPKI $\gamma$ [42]. It is plausible that PIPKI $\gamma$ plays a role in invadopodia formation by production of $\mathrm{PI} 4,5 \mathrm{P}_{2}$ that regulates actin filament dynamics via cofilin, $\alpha$-actinin, and vinculin.

The PIPKI $\gamma$ expression is correlated with E-cadherin in our tissue microarray results. It is consistent with the role of PIPKI $\gamma$ in regulating E-cadherin trafficking. PIP$\mathrm{KI} \gamma$ binds directly to E-cadherin and recruits clathrin adaptor complexes AP1B to the E-cadherin-PIPKI $\gamma$ complex and this controls the targeting of E-cadherin to the basolateral membrane $[14,16]$. The loss of PIPKI $\gamma$ results in the loss of E-cadherin targeting to the plasma membrane and a loss of epithelial cell polarization. The PIP$\mathrm{KI} \gamma$-interacting region in E-cadherin has some overlapping with $\beta$-catenin-binding domain [16]. PIPKI $\gamma$ may regulate E-cadherin- $\beta$-catenin interaction and then 


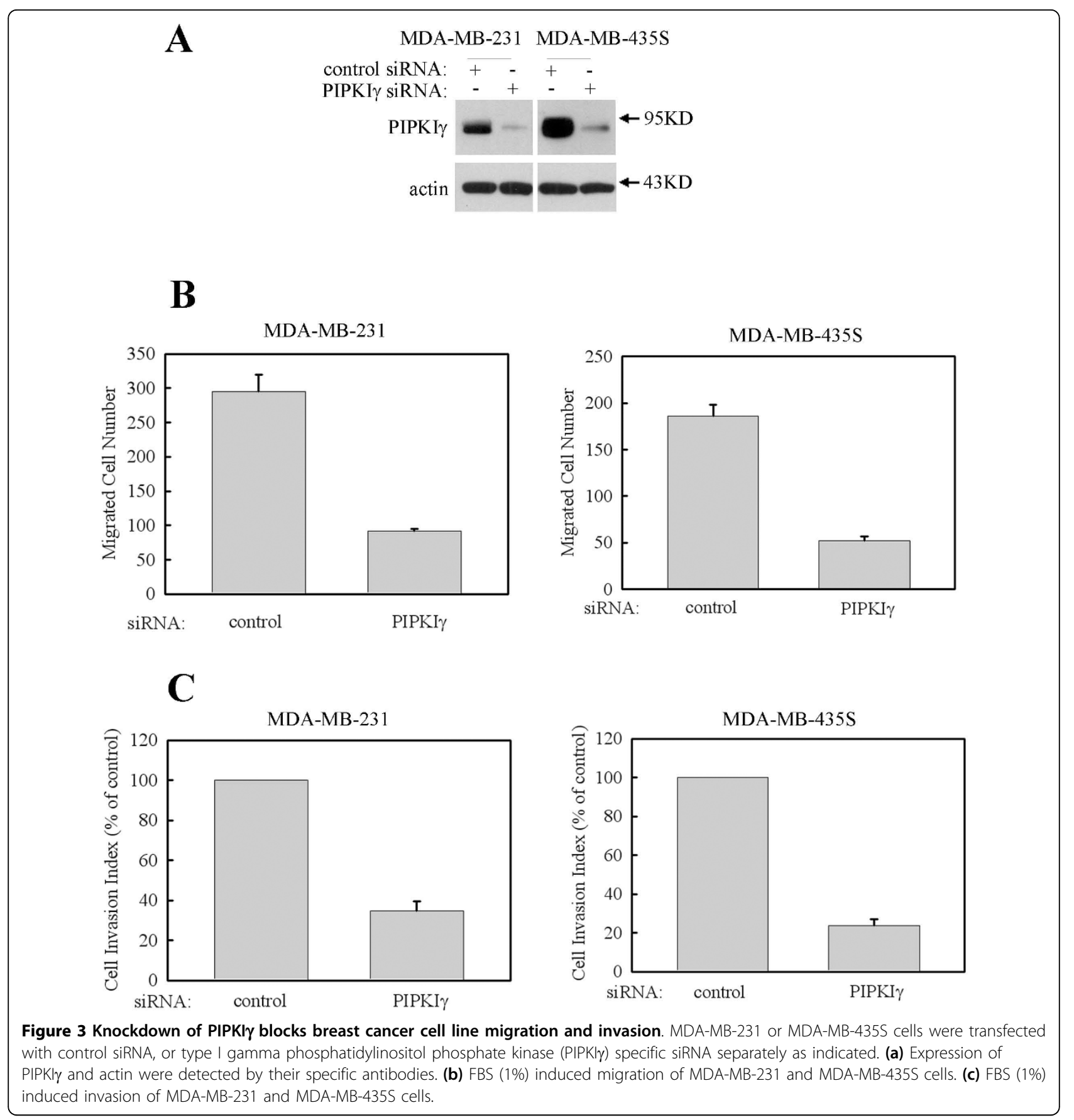

modulate $\beta$-catenin nuclear translocation. Transactivation of $\beta$-catenin correlated significantly with cyclin D1 expression, and that high $\beta$-catenin activity significantly correlated with poor prognosis of the patients and was a strong and independent prognostic factor in breast cancer [43]. PIPKI $\gamma$ may regulate breast cancer progression via $E$-cadherin- $\beta$-catenin signal pathway.

Breast cancers are heterogeneous in their ER and PR status and display different response to tamoxifen treatment [44]. A study on the cellular phenotypes of breast cancer tumors in 19,541 white women with node-negative disease showed that $\mathrm{ER}+/ \mathrm{PR}+$ is the most common phenotype of breast cancer constituting $66 \%$ of the tumors, followed by ER-/PR- (19\%), ER+/PR- (12.5\%), and ER-/PR+ (3.4\%). Among these different tumors, ER-/PR- tumors are associated with the worst cancerspecific survival and are resistant to tamoxifen treatment [45]. Our results show that higher expression of PIPKI $\gamma$ correlates to lower expression of ER and/or PR and correlates to lower patient survival rates. It is consistent 
A

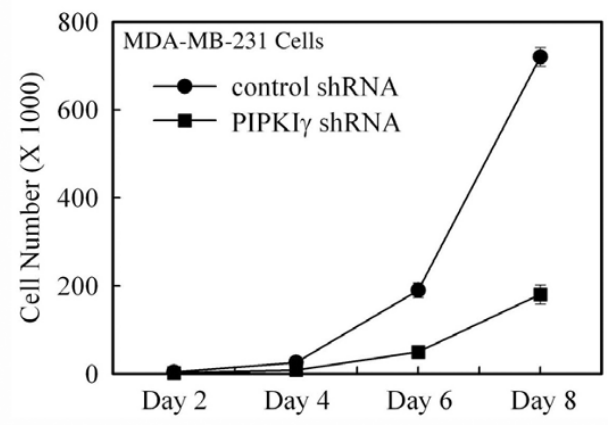

B

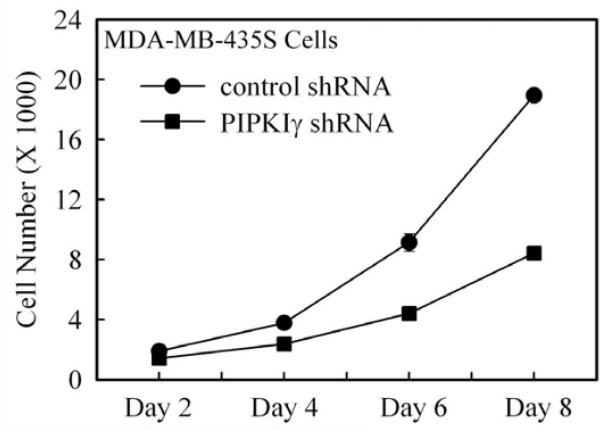

C

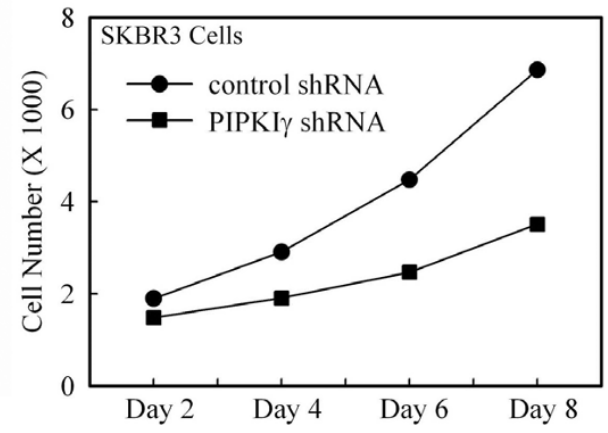

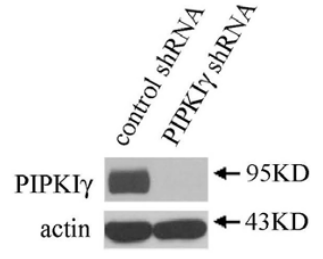
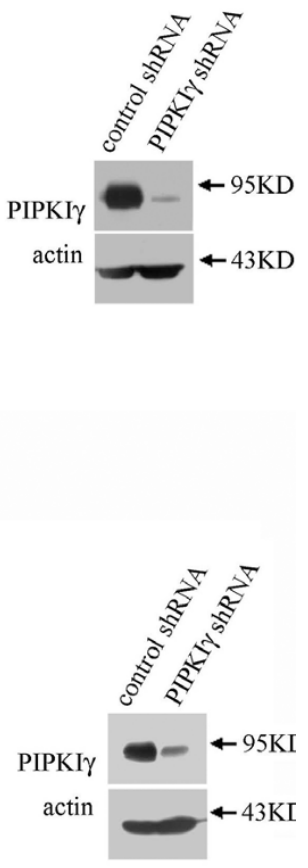

Figure 4 PIPKI $\gamma$ expression is required for rapid cell proliferation in breast cancer cells. Lentiviral vector was used to generate the stable knockdown of type I gamma phosphatidylinositol phosphate kinase (PIPKl $\gamma$ ) in breast cancer cell lines as described in "Material and methods". Decreased expression of PIPKl $\gamma$ was assessed by using PIPKI $\gamma$ specific antibody. Cells infected with either Control short-hairpin RNA (shRNA) or PIPKl $\gamma$ shRNA were seeded into 12-well culture plates at a density of 1000 cells/well. Manual cell counting was performed every two days for the eight days. The cell numbers were counted from at least three wells for each cell type and expressed as mean \pm standard deviation from one representative experiment. (a) MDA-MB-231 cells. (b) MDA-MB-435S cells. (c) SKBR3 cells.

with the fact that ER-/PR-tumors are associated with poor breast cancer prognosis. Although it is not clear if PIPKI $\gamma$ could directly modulate ER or PR expression and if PIPKI $\gamma$ could regulate ER or PR signaling, our results provide evidence that PIPKI $\gamma$ correlates with ovarian hormone receptors status. It is worthy to demonstrate the possible role of PIPKI $\gamma$ in regulating ovarian hormone pathways in breast cancer progression.

\section{Conclusions}

The inverse correlation between strong PIPKI $\gamma$ expression and overall patient survival is consistent with the finding that PIPKI $\gamma$ is required for breast epithelial cell adherent junction assembly, growth factor stimulated migration, invasion, and proliferation. This study provides evidence of the pathological significance of PIPKI $\gamma$ in breast cancer progression. 


\section{Abbreviations}

ARF6: ADP-ribosylation factor 6; BSA: bovine serum albumin; DMEM:

Dulbecco's modified eagle medium; EGFR: epidermal growth factor receptor; ER: estrogen receptor; FBS: fetal bovine serum; HER: human epidermal growth factor receptor; PBS: phosphate-buffered saline; PI4, 5 $\mathrm{P}_{2}$ phosphatidylinositol 4,5-bisphosphate; PIPKly: type I gamma phosphatidylinositol phosphate kinase; PR: progesterone receptor; shRNA: short-hairpin RNA.

\section{Acknowledgements}

This work was funded by NIH grants GM057549 and CA104708.

\section{Author details}

${ }^{1}$ Department of Pharmacology, University of Wisconsin Medical School, 1300 University Avenue, Madison, Wisconsin, 53706, USA. ${ }^{2}$ Genetic Pathology Evaluation Centre of the Prostate Centre, University of British Columbia, Room 509, JBRC, 2660 Oak St., Vancouver, BC, V6H 3Z6, Canada.

\section{Authors' contributions}

YS wrote the manuscript, performed the breast cancer migration and invasion assay. DT performed TMA and analyzed the statistical data and helped to draft the manuscript. KL provided the anti-PIPKI $\gamma$ antibodies and helped to draft the manuscript. NT performed breast cancer proliferation assay. SL helped to perform TMA and analyze the statistical data. DH and RAA are the research group leaders, evaluated the data, edited and approved the final manuscript to be published. All authors read and approved the final manuscript.

\section{Competing interests}

The authors declare that they have no competing interests.

Received: 2 October 2009 Revised: 4 January 2010

Accepted: 14 January 2010 Published: 14 January 2010

\section{References}

1. Jemal A, Clegg LX, Ward E, Ries LA, Wu X, Jamison PM, Wingo PA, Howe HL, Anderson RN, Edwards BK: Annual report to the nation on the status of cancer, 1975-2001, with a special feature regarding survival. Cancer 2004, 101:3-27.

2. Paulson KE, Rieger-Christ K, McDevitt MA, Kuperwasser C, Kim J, Unanue VE, Zhang X, Hu M, Ruthazer R, Berasi SP, Huang CY, Giri D, Kaufman S, Dugan JM, Blum J, Netto G, Wazer DE, Summerhayes IC, Yee AS: Alterations of the HBP1 transcriptional repressor are associated with invasive breast cancer. Cancer Res 2007, 67:6136-6145.

3. Coleman RE: Future directions in the treatment and prevention of bone metastases. Am J Clin Oncol 2002, 25:S32-38.

4. Mundy GR: Metastasis to bone: causes, consequences and therapeutic opportunities. Nat Rev Cancer 2002, 2:584-593.

5. Kuperwasser C, Dessain S, Bierbaum BE, Garnet D, Sperandio K, Gauvin GP, Naber SP, Weinberg RA, Rosenblatt M: A mouse model of human breast cancer metastasis to human bone. Cancer Res 2005, 65:6130-6138.

6. Keshtgar MR, Ell PJ: Sentinel lymph node detection and imaging. Eur J Nucl Med 1999, 26:57-67.

7. Pathak AP, Artemov D, Neeman M, Bhujwalla ZM: Lymph node metastasis in breast cancer xenografts is associated with increased regions of extravascular drain, lymphatic vessel area, and invasive phenotype. Cancer Res 2006, 66:5151-5158.

8. Ling K, Schill NJ, Wagoner MP, Sun Y, Anderson RA: Movin' on up: the role of Ptdlns(4,5)P(2) in cell migration. Trends Cell Biol 2006, 16:276-284.

9. Wang W, Eddy R, Condeelis J: The cofilin pathway in breast cancer invasion and metastasis. Nat Rev Cancer 2007, 7:429-440

10. van Rheenen J, Song X, van Roosmalen W, Cammer M, Chen X, Desmarais V, Yip SC, Backer JM, Eddy RJ, Condeelis JS: EGF-induced PIP2 hydrolysis releases and activates cofilin locally in carcinoma cells. J Cell Biol 2007, 179:1247-1259.

11. Niggli V: Regulation of protein activities by phosphoinositide phosphates. Annu Rev Cell Dev Biol 2005, 21:57-79.

12. Doughman RL, Firestone AJ, Anderson RA: Phosphatidylinositol phosphate kinases put PI4,5P(2) in its place. J Membr Biol 2003, 194:77-89.

13. Bairstow SF, Ling K, Anderson RA: Phosphatidylinositol phosphate kinase type Igamma directly associates with and regulates Shp-1 tyrosine phosphatase. J Biol Chem 2005, 280:23884-23891.
14. Bairstow SF, Ling K, Su X, Firestone AJ, Carbonara C, Anderson RA: Type Igamma661 phosphatidylinositol phosphate kinase directly interacts with AP2 and regulates endocytosis. J Biol Chem 2006, 281:20632-20642.

15. El Sayegh TY, Arora PD, Ling K, Laschinger C, Janmey PA, Anderson RA, McCulloch CA: Phosphatidylinositol-4,5 bisphosphate produced by PIP5KIgamma regulates gelsolin, actin assembly, and adhesion strength of N-cadherin junctions. Mol Biol Cell 2007, 18:3026-3038.

16. Ling K, Bairstow SF, Carbonara C, Turbin DA, Huntsman DG, Anderson RA: Type Igamma phosphatidylinositol phosphate kinase modulates adherens junction and E-cadherin trafficking via a direct interaction with mu 1B adaptin. J Cell Biol 2007, 176:343-353.

17. Ling K, Doughman RL, Firestone AJ, Bunce MW, Anderson RA: Type I gamma phosphatidylinositol phosphate kinase targets and regulates focal adhesions. Nature 2002, 420:89-93.

18. Ling K, Doughman RL, lyer W, Firestone AJ, Bairstow SF, Mosher DF, Schaller MD, Anderson RA: Tyrosine phosphorylation of type Igamma phosphatidylinositol phosphate kinase by Src regulates an integrin-talin switch. J Cell Biol 2003, 163:1339-1349.

19. Wang Y, Lian L, Golden JA, Morrisey EE, Abrams CS: PIP5KI gamma is required for cardiovascular and neuronal development. Proc Natl Acad Sci USA 2007, 104:11748-11753.

20. Wang Y, Litvinov RI, Chen X, Bach TL, Lian L, Petrich BG, Monkley SJ, Kanaho Y, Critchley DR, Sasaki T, Birnbaum MJ, Weisel JW, Hartwig J, Abrams CS: Loss of PIP5KIgamma, unlike other PIP5KI isoforms, impairs the integrity of the membrane cytoskeleton in murine megakaryocytes. $J$ Clin Invest 2008, 118:812-819.

21. Ishihara H, Shibasaki Y, Kizuki N, Wada T, Yazaki Y, Asano T, Oka Y: Type I phosphatidylinositol-4-phosphate 5-kinases. Cloning of the third isoform and deletion/substitution analysis of members of this novel lipid kinase family. J Biol Chem 1998, 273:8741-8748.

22. Schill NJ, Anderson RA: Two novel phosphatidylinositol 4-phosphate, 5kinase type I gamma splice variants expressed in human cells display distinctive cellular targeting. Biochem J 2010.

23. Wang YJ, Li WH, Wang J, Xu K, Dong P, Luo X, Yin HL: Critical role of PIP5KI\{gamma\}87 in InsP3-mediated Ca(2+) signaling. J Cell Biol 2004, 167:1005-1010.

24. Di Paolo G, Pellegrini L, Letinic K, Cestra G, Zoncu R, Voronov S, Chang S, Guo J, Wenk MR, De Camilli P: Recruitment and regulation of phosphatidylinositol phosphate kinase type 1 gamma by the FERM domain of talin. Nature 2002, 420:85-89.

25. Sun Y, Ling K, Wagoner MP, Anderson RA: Type I gamma phosphatidylinositol phosphate kinase is required for EGF-stimulated directional cell migration. J Cell Biol 2007, 178:297-308.

26. Macaluso M, Paggi MG, Giordano A: Genetic and epigenetic alterations as hallmarks of the intricate road to cancer. Oncogene 2003, 22:6472-6478.

27. Zhang X, Loijens JC, Boronenkov IV, Parker GJ, Norris FA, Chen J, Thum O, Prestwich GD, Majerus PW, Anderson RA: Phosphatidylinositol-4phosphate 5-kinase isozymes catalyze the synthesis of 3-phosphatecontaining phosphatidylinositol signaling molecules. J Biol Chem 1997, 272:17756-17761.

28. Makretsov NA, Huntsman DG, Nielsen TO, Yorida E, Peacock M, Cheang MC, Dunn SE, Hayes M, Rijn van de M, Bajdik C, Gilks CB: Hierarchical clustering analysis of tissue microarray immunostaining data identifies prognostically significant groups of breast carcinoma. Clin Cancer Res 2004, 10:6143-6151.

29. Ng TL, Gown AM, Barry TS, Cheang MC, Chan AK, Turbin DA, Hsu FD, West RB, Nielsen TO: Nuclear beta-catenin in mesenchymal tumors. Mod Pathol 2005, 18:68-74.

30. TMA Reviewer. https://www.gpecimage.ubc.ca/tma/web/viewer.php.

31. Neptune ER, Bourne HR: Receptors induce chemotaxis by releasing the betagamma subunit of $\mathrm{Gi}$, not by activating $\mathrm{Gq}$ or Gs. Proc Natl Acad Sci USA 1997, 94:14489-14494.

32. Sun $Y$, Cheng $Z$, Ma L, Pei G: Beta-arrestin 2 is critically involved in CXCR4mediated chemotaxis, and this is mediated by its enhancement of p38 MAPK activation. J Biol Chem 2002, 277:49212-49219.

33. Turbin DA, Leung $S$, Cheang MC, Kennecke HA, Montgomery KD, McKinney S, Treaba DO, Boyd N, Goldstein LC, Badve S, Gown AM, Rijn van de M, Nielsen TO, Gilks CB, Huntsman DG: Automated quantitative analysis of estrogen receptor expression in breast carcinoma does not differ from expert pathologist scoring: a tissue microarray study of 3,484 cases. Breast Cancer Res Treat 2008, 110:417-426. 
34. Abd El-Rehim DM, Pinder SE, Paish CE, Bell JA, Rampaul RS, Blamey RW, Robertson JF, Nicholson RI, Ellis IO: Expression and co-expression of the members of the epidermal growth factor receptor (EGFR) family in invasive breast carcinoma. Br J Cancer 2004, 91:1532-1542.

35. Tsutsui S, Kataoka A, Ohno S, Murakami S, Kinoshita J, Hachitanda Y: Prognostic and predictive value of epidermal growth factor receptor in recurrent breast cancer. Clin Cancer Res 2002, 8:3454-3460.

36. Brandt BH, Roetger A, Dittmar T, Nikolai G, Seeling M, Merschjann A, Nofer JR, Dehmer-Moller G, Junker R, Assmann G, Zaenker KS: c-erbB-2/ EGFR as dominant heterodimerization partners determine a motogenic phenotype in human breast cancer cells. FASEB J 1999, 13:1939-1949.

37. Cotterchio M, Kreiger N, Theis B, Sloan M, Bahl S: Hormonal factors and the risk of breast cancer according to estrogen- and progesteronereceptor subgroup. Cancer Epidemiol Biomarkers Prev 2003, 12:1053-1060.

38. Onitilo AA, Engel JM, Greenlee RT, Mukesh BN: Breast cancer subtypes based on ER/PR and Her2 expression: comparison of clinicopathologic features and survival. Clin Med Res 2009, 7:4-13.

39. Klijn JG, Look MP, Portengen $H$, Alexieva-Figusch J, van Putten $W L$, Foekens JA: The prognostic value of epidermal growth factor receptor (EGF-R) in primary breast cancer: results of a 10 year follow-up study. Breast Cancer Res Treat 1994, 29:73-83.

40. Coopman PJ, Thomas DM, Gehlsen KR, Mueller SC: Integrin alpha 3 beta 1 participates in the phagocytosis of extracellular matrix molecules by human breast cancer cells. Mol Biol Cell 1996, 7:1789-1804.

41. Hashimoto S, Onodera Y, Hashimoto A, Tanaka M, Hamaguchi M, Yamada A, Sabe H: Requirement for Arf6 in breast cancer invasive activities. Proc Natl Acad Sci USA 2004, 101:6647-6652.

42. Krauss M, Kinuta M, Wenk MR, De Camilli P, Takei K, Haucke V: ARF6 stimulates clathrin/AP-2 recruitment to synaptic membranes by activating phosphatidylinositol phosphate kinase type Igamma. J Cell Biol 2003, 162:113-124

43. Lin SY, Xia W, Wang JC, Kwong KY, Spohn B, Wen Y, Pestell RG, Hung MC: Beta-catenin, a novel prognostic marker for breast cancer: its roles in cyclin D1 expression and cancer progression. Proc Natl Acad Sci USA 2000, 97:4262-4266.

44. Cordera F, Jordan VC: Steroid receptors and their role in the biology and control of breast cancer growth. Semin Oncol 2006, 33:631-641.

45. Anderson WF, Chu KC, Chatterjee N, Brawley O, Brinton LA: Tumor variants by hormone receptor expression in white patients with node-negative breast cancer from the surveillance, epidemiology, and end results database. J Clin Oncol 2001, 19:18-27.

doi:10.1186/bcr2471

Cite this article as: Sun et al:: Type I gamma phosphatidylinositol phosphate kinase modulates invasion and proliferation and its expression correlates with poor prognosis in breast cancer. Breast Cancer Research 2010 12:R6.

\section{Submit your next manuscript to BioMed Central and take full advantage of:}

- Convenient online submission

- Thorough peer review

- No space constraints or color figure charges

- Immediate publication on acceptance

- Inclusion in PubMed, CAS, Scopus and Google Scholar

- Research which is freely available for redistribution

Submit your manuscript at www.biomedcentral.com/submit
Biomed Central 